\title{
Spatial pattern and Factors associated with khat chewing among adult males 15-59 years in Ethiopia, EDHS 2016. Generalized Estimating Equation Approach
}

\section{Zemenu Tessema Tadesse ( $\nabla$ zemenut1979@gmail.com ) \\ University of Gondar https://orcid.org/0000-0003-3878-7956 \\ Tadele Amare Zeleke \\ University of Gondar College of Natural and Computational Sciences}

\section{Research}

Keywords: Khat, Spatial distribution, Factors, Ethiopia

Posted Date: January 21st, 2020

DOI: https://doi.org/10.21203/rs.2.21460/v1

License: (a) (1) This work is licensed under a Creative Commons Attribution 4.0 International License.

Read Full License 


\section{Abstract}

Background Khat chewing has become prevalent in the world due to the improvement of road and air transportation. In Ethiopia, khat chewing is more prevalent and wildly practiced by men. Khat has a negative effect on social, economic and mental health. Therefore, this study aims to show spatial patterns and factors associated with khat chewing among male adults 15-59 years in Ethiopia.

Methods A total of 12,594 men who chew khat in their were included in this study. ArcGIS version 10.7 software was used to visualize spatial pattern chewing khat among adult men in Ethiopia. The Bernoulli model was applied using Kilduff SaTScan version 9.6 software to identify significant purely spatial clusters for chewing khat in Ethiopia. The robust standard error method of generalized estimating equations was used for the binary outcome variable from the clustered data and adjusted odds ratios with $95 \%$ confidence interval were reported.

Results A total of 12,594 participants were included in the analysis. The prevalence of ever khat chewing in this study was 3418 (27.14\%) with $95 \% \mathrm{Cl} 26.37 \%$ to $27.92 \%$. From EDHS 2016 survey the high proportion of chewing khat was located in Diredawa, Harari, Southern Oromia, Somai and Benishangu Gumuz Regions. In spatial scan statistics analysis, a total of 126 clusters ( $R R=4.02$, P-value $<0.001)$ was identified. Age group 30-44 (AOR=1.44, 95\% Cl: 1.27, 1.62), being single (AOR=1.86, 95\% Cl: 1.64, 2.12), Muslim religion ( $\mathrm{AOR}=4.91,95 \% \mathrm{Cl}$ : 3.69, 8.19), media exposure ( $\mathrm{AOR}=0.77,95 \% \mathrm{Cl}: 0.68,0.86$ ), working status(AOR=0.45, 95\% Cl: 0.39, 0.53), alcohol drinking (AOR=2.91, 95\% Cl: $2.43,3.39)$ and region were statistically significant factors affecting chewing Khat in Ethiopia.

Conclusions The prevalence of chewing chat in Ethiopia was high and located in Diredawa, Harari, Southern Oromia, Somai and Benishangu Gumuz Regions. Older age group, single, drinker, media unexposed, had no work and Muslim religion follower should be given spatial attention in reducing the prevalence of chewing khat. Therefore, it is good to teach the health impact of khat chewing through media.

\section{Background}

Khat(Catha edulis Forsk) is a flowering evergreen shrub that belongs to the family Celastraceae. It grows wild or cultivated countries bordering the Red Sea and the East Coast of Africa. Depend on its origin; there are several names of the plant: qat, chat, jaad, qaad, miraa, mairungi, cat, Catha, gat, tschat and kat(1-3).

Khat comprises a psychoactive substance composite belonging to the phenyl propylamine groups of alkaloids called cathinone which has amphetamine like -effect. It sources mild euphoric and wakefulness $(4,5)$.

Khat is widely grown in Ethiopia, Somalia, Kenya, Yemen, Sudan, South Africa, and Madagascar. Nowadays, due to globalization (improved roads and air transport) have allowed a much wider distribution of khat in the world $(2,6)$. 
Khat was being used in Yemen in the $6^{\text {th }}$ century. In 1775, khat first came to the attention of the nonArabic world when its use was characterized by European botanists visiting Yemen(7).

Even though the exact number is not known, approximately 5 to 10 million people use khat in the world(8).

According to the United Nations, Office on Drugs and Crime reported that approximately $72 \%$ of Yemeni men and $32.6 \%$ of women used khat in 2006(9). In other study chewing khat among Yemeni men and women was $90 \%$ and $60 \%$ respectively $(10)$. Somalis living in London, $67 \%$ had used khat a week prior to the interview(11). In Saudi Arabia, the prevalence of current khat use among men was $36.9 \%(12)$.

In Ethiopia according to the Ethiopian Demographic Health Survey, the prevalence of khat use among adults in the last 30 days was $15.3 \%(13)$. another survey, on the 2015 national non-communicable disease STEPS survey showed that $12.3 \%$ of the male was ever khat users(14). The prevalence of ever khat use among men was in Jimma town was $27.8 \%(15)$. In Nekemt town the current user of khat was $43.5 \%(16)$, in Butajira ever khat chew was $55.7 \%$ in both males and females (17) and in Dera woreda, the prevalence of ever khat use was $19.9 \%$ in both male and female(18).

Reasons for khat use were peer pressure, academic performance, alertness, feeling excitement and wellbeing $(19,20)$.

The consequence of khat chewing was absenteeism from workplace, carelessness, poor interaction with others, depression, anxiety, sleep disorder, poor confidence, socio-economic problems, conflict in the family, reduced appetite neurological, dental, gastrointestinal, cardiovascular, underweight and genitourinary effects(21-24).

\section{Factors associated with khat use}

Alcohol drinker(25), Muslim religion follower, age 45 to 49, attended mass media had significantly associated with khat use $(13,18,19)$. In Ethiopian regions; Oromia, South Nation Nationalities and People (SNNP), Gambella, Harari, and Dire Dawa were also significant factors for khat use(13).

In Ethiopia, especially in the Amhara region the regional government-imposed policy and increased taxation. Although some intervention was practiced, the global and national prevalence was still increased and shreds of evidence were limited. Therefore, the aim of this study was to assess the spatial pattern and factors associated with khat chewing among adults age 15-59 years in Ethiopia. 


\section{Methods}

\section{Study design, period and setting}

A Population-based cross-sectional study was conducted from January 18 to June 27, 2016. Ethiopia is located in the horn of Africa. It has a total area of $1,100,000 \mathrm{~km} 2$ and lies between latitudes $3^{\circ}$ and $15^{\circ} \mathrm{N}$, and longitudes $33^{\circ}$ and $48^{\circ} \mathrm{E}$. Ethiopia has been divided into nine ethnic-based and politically autonomous regional states (Afar, Amhara, Benishangul Gumuz, Gambela, Harari, Oromia, Somali, Southern Nations, Nationalities, and People's Region (SNNP) and Tigray) and two cities (Addis Ababa and Dire Dawa)(Figure1).

\section{Population, sample size, and sampling technique}

All men from 15 to 59 years in Ethiopia were the source population. Whereas, all men age 15-59 in the selected enumeration areas were the study population. All men age 15-59 who had interviewed ever chewed khat were included in the study. However, respondents with missing data for the outcome variable were excluded from the study.

The 2016 EDHS sample is stratified and was selected in two stages. Regions were stratified into urban and rural areas, which yielded 21 sampling strata. Samples of EAs were selected independently in each stratum in two stages. In the first stage, 645 EAs were selected proportional allocation to the EA size and with independent selection in each sampling stratum. A household listing operation was implemented in the selected EAs, and the resulting lists of households served as the sampling frame for the selection of households in the second stage.

\section{Study variables}

Respondents ever chat chewing status, the outcome variable in this study was defined as a person who ever chewed khat in his lifetime. The independent variables were grossly classified into sociodemographic and economic factors: age, religion, marital status, educational status, place of residence, region, and Behavioral factors: alcohol drinking, source of information: reading newspaper, reading magazines, and watching television. Wealth ranking was grossly categorized into 5 major quintiles based on household assets as lowest (poorest), second (poorer), middle (middle), fourth (richer), and highest (richest) we recategorized in to three poor (poorest + poor), middle and rich (richest + rich) for ease of analysis.

\section{Operational Definition}

Ever chat chewer. Was defined as a respondent whoever chewed chat during his lifetime.

Alcohol drinking: was defined as a respondent who drunk during one month preceding the survey at least once per month. 


\section{Data collection tool and procedure}

Raw data collected from all parts of the country on Men's whose age between 15-59 were extracted from 2016 EDHS by properly trained data collectors using standardized, structured, and pre-tested questionnaires. Initially, before the start of fieldwork, questionnaires were pretested

\section{Spatial Analysis}

\section{Spatial distribution of Khat chewing in Ethiopia}

Among a total of 643 clusters, 621 were considered for the spatial analysis of khat chewing in Ethiopia( 21 clusters dropped because of no coordinate data in that cluster). Each point on the map represents one enumeration area with a prevalence of khat chewing in each cluster.

\section{Spatial autocorrelation analysis}

The spatial autocorrelation (Global Moran's I) statistic measures whether khat chewing patterns were dispersed, clustered or randomly distributed in the study area(1). Moran's I is a spatial statistics used to measure spatial autocorrelation by taking the entire data set and produce a single output value which ranges from -1 to +1 . Moran's I Values close to -1 indicate disease dispersed, whereas I close to +1 indicate disease clustered and disease distributed randomly if I value is zero. A statistically significant Moran's I $(p<0.05)$ leads to rejection of the null hypothesis (khat chewing is randomly distributed) and indicates the presence of spatial autocorrelation

\section{Incremental autocorrelation}

Measures spatial autocorrelation for a series of distances and optionally creates a line graph of those distances and their corresponding z-scores. Z-scores reflect the intensity of spatial clustering, and statistically significant peak $z$-scores indicate distances where spatial processes promoting clustering are most pronounced. These peak distances are often appropriate values to use for tools with a Distance Band or Distance Radius parameter. This tool can help you select an appropriate Distance Threshold or Radius for tools that have these parameters, such as hot spot analysis(1).

\section{Hot spot analysis (Getis-OrdGi* statistic)}

Getis-OrdGi* statistics was computed to measure how spatial autocorrelation varies over the study location by calculating $\mathrm{Gl}^{\star}$ statistic for each area. Z-score is computed to determine the statistical significance of clustering, and the p-value computed for the significance. Statistical output with high $\mathrm{Gl}{ }^{\star}$ indicates "hotspot" whereas low Gl* means a "cold spot" 


\section{Spatial scan statistical analysis}

A Bernoulli-based model was used in which events at particular places were analyzed if adults weather chewing chat or not coded as $1 / 0$ variable. The scan statistics developed by Kulldorff and SaTScan ${ }^{\text {TM }}$ software version 9.6 were used to identify the presence of purely spatial home deliver clusters. Scan statistics did scanning gradually across the space to identify the number of observed and expected observations inside the window at each location. The scanning window with the maximum likelihood was the most likely high performing clusters, and a p-value was assigned to this cluster.

\section{Spatial interpolation:}

The spatial interpolation technique is used to predict khat chewing for unsampled areas based on sampled EAs. For the prediction of unsampled EAs, we used deterministic and geostatistical Ordinary Kriging spatial interpolation technique using ArcGIS 10.7 software

\section{Data processing and Statistical analysis}

STATA version 14.1, excel and ArcGIS 10.1 were used for statistical and spatial analysis. Then data cleaning was carried out. Both descriptive and analytical studies were done after the data was weighted and presented on texts, tables, and graphs. Both bi-variable and multivariable analyses were performed to determine the existing association. Initially, bivariate analysis was performed and variables with a p-value of 0.2 and below were used for further analysis in the multivariable model. At the same time, Crude Odds Ratio (COR) and Adjusted Odds Ratio (AOR) with their corresponding confidence interval (Cl) also determined for the bivariate and multivariate analysis, respectively. Finally, a p-value less than 0.05 level of significance was used to declare the significance of association in the multi-variable model. The clustering effect was tested based on the region as a clustering variable. The robust standard error method of generalized estimating equations was used for the binary outcome variable from the clustered data.

\section{Results}

A total of 12,594 participants were included in the analysis. The prevalence of ever khat chewing in this study was 3418 (27.14\%) with $95 \% \mathrm{Cl} 26.37 \%$ to $27.92 \%$. Majority of them, 6426 (51.03\%) of participants were in the age of 15-29 years. The majority of the participants $10098(80.18 \%)$ were from rural and most of them $5876(46.66 \%)$ were in the primary education class. The median age of the respondent was 29 with inter-quartile range (IQR) of 21-39. Around two-third of 7705(61.17\%), of participants, were married (Table 1).

Table 1: socio-demographic and behavioral factors of adult men 15-59 years in Ethiopia, EDHS 2016 


\begin{tabular}{|c|c|c|}
\hline Variable & Frequency $(n=12,594)$ & Percentage \\
\hline \multicolumn{3}{|l|}{ Ever chewed khat } \\
\hline Yes & 3418 & 27.14 \\
\hline No & 9176 & 72.86 \\
\hline \multicolumn{3}{|l|}{ Age group } \\
\hline $15-29$ & 6426 & 51.03 \\
\hline $30-44$ & 4173 & 33.13 \\
\hline $45-59$ & 1995 & 15.84 \\
\hline \multicolumn{3}{|l|}{ Sex of the household } \\
\hline Male & 11034 & 87.61 \\
\hline Female & 1560 & 12.59 \\
\hline \multicolumn{3}{|l|}{ Marital Status } \\
\hline Married & 7705 & 61.17 \\
\hline Single & 489 & 38.83 \\
\hline \multicolumn{3}{|l|}{ Residence } \\
\hline Urban & 2496 & 19.82 \\
\hline Rural & 10098 & 80.18 \\
\hline \multicolumn{3}{|l|}{ Religion } \\
\hline Orthodox & 5677 & 45.07 \\
\hline Muslim & 3916 & 31.09 \\
\hline Protestant & 2745 & 21.80 \\
\hline Others* & 256 & 2.03 \\
\hline \multicolumn{3}{|l|}{ Education } \\
\hline No education & 3773 & 29.06 \\
\hline Primary & 5876 & 46.66 \\
\hline Secondary & 1846 & 14.66 \\
\hline Higher & 1099 & 8.73 \\
\hline \multicolumn{3}{|l|}{ Region } \\
\hline Tigray & 795 & 6.31 \\
\hline Afar & 82 & 0.65 \\
\hline Amhara & 3206 & 25.46 \\
\hline Oromia & 4713 & 37.43 \\
\hline Somali & 326 & 2.59 \\
\hline
\end{tabular}




\begin{tabular}{|c|c|c|}
\hline Benishangul & 123 & 0.98 \\
\hline SNNPR & 2886 & 20.53 \\
\hline Gambela & 36 & 0.29 \\
\hline Harari & 31 & 0.25 \\
\hline Addis Ababa & 196209 & 4.93 \\
\hline Dire-Dawa & 71 & 0.57 \\
\hline \multicolumn{3}{|l|}{ Media Exposure } \\
\hline Yes & 8154 & 64.74 \\
\hline No & 4440 & 35.26 \\
\hline \multicolumn{3}{|l|}{ Wealth Index } \\
\hline Poor & 4272 & 33.92 \\
\hline Middle & 2427 & 19.27 \\
\hline Rich & 5895 & 46.81 \\
\hline \multicolumn{3}{|l|}{ Working Status } \\
\hline Yes & 11172 & 88.71 \\
\hline No & 1422 & 11.29 \\
\hline \multicolumn{3}{|l|}{ Alcohol drinking } \\
\hline Yes & 5873 & 46.64 \\
\hline No & 6721 & 53.36 \\
\hline
\end{tabular}




\section{Spatial Distribution of Khat chewing}

Among a total of 643 clusters, 621 were considered for the spatial analysis of khat chewing in Ethiopia( 21 clusters dropped because of no coordinate data in that cluster). Each point on the map represents one enumeration area with a prevalence of khat chewing in each cluster. The red color indicates areas with a high proportion of khat chewer whereas green color indicates EAs with a lower proportion of khat chewers. (Figure.2)

\section{Spatial autocorrelation of Khat chewing}

The spatial distribution of Khat chewing in Ethiopia was non-random in the EDHS 2016 survey. The global Moran's I value was 0.49 (P-value < 0.001 ) with z-score value 30.63 with that there is a less than $1 \%$ likelihood that this clustered pattern could be the result of chance (Figure3).

\section{Incremental Spatial Autocorrelation Khat chewing}

To determine spatial clustering for khat chewing, global spatial statistics were estimated using Moran's I value. As shown in the figure below a statistically significant z-scores indicate at $357.42 \mathrm{Km}$ distances where spatial processes promoting clustering are most pronounced. The incremental spatial Autocorrelation indicates that a total of 10 distance bands were detected with a beginning distance of 357428.11 meters. (Figure 4)

\section{Hot spot analysis (Getis-OrdGi* statistic)}

As shown in the figure below, the red color indicates the more intense clustering of high (hot spot) proportion of khat chewing in the five years preceding the survey period and observed in Diredawa, Harari, Southern Oromia, Somai and Benishangu Gumuz Regions. (Figure 5)

\section{Spatial scan statistical analysis}

As shown in figure 6 below, the red window indicates the identified significant clusters inside the window. In spatial scan statistics, a total of 140 most likely clusters were identified in EDHS 2016 survey. The most likely clusters of khat chewing were detected in most parts of Harari, Dire Dawa, southwestern part of Oromia, SNNPR, and Somali regions. Among the most likely clusters, 126 of them were primary clusters which are located at $9.303717 \mathrm{~N}, 41.792390 \mathrm{E}$ with a $200.29 \mathrm{~km}$ radius (Relative risk (RR) = 4.02 and Log-Likelihood ratio $(L L R)=480.60$, P-value $<0.001)$. In EDHS 2016, mothers live in the primary cluster were 4.02 times more likely to chew khat than outside the window(Figure 6 and Table 2). 
Table 2: SaT Scan analysis of khat chewing among men in the last five years in Ethiopia, EDHS2016

\begin{tabular}{|c|c|c|c|c|c|c|c|}
\hline $\begin{array}{l}\text { Cluster } \\
\text { type }\end{array}$ & $\begin{array}{l}\text { Significant } \\
\text { Enumeration } \\
\text { Areas(clusters) } \\
\text { detected }\end{array}$ & $\begin{array}{l}\text { Coordinates } \\
\text { /Radis }\end{array}$ & Populations & Cases & RR & LLR & $\begin{array}{l}\mathrm{P} \text { - } \\
\text { value }\end{array}$ \\
\hline Primary & 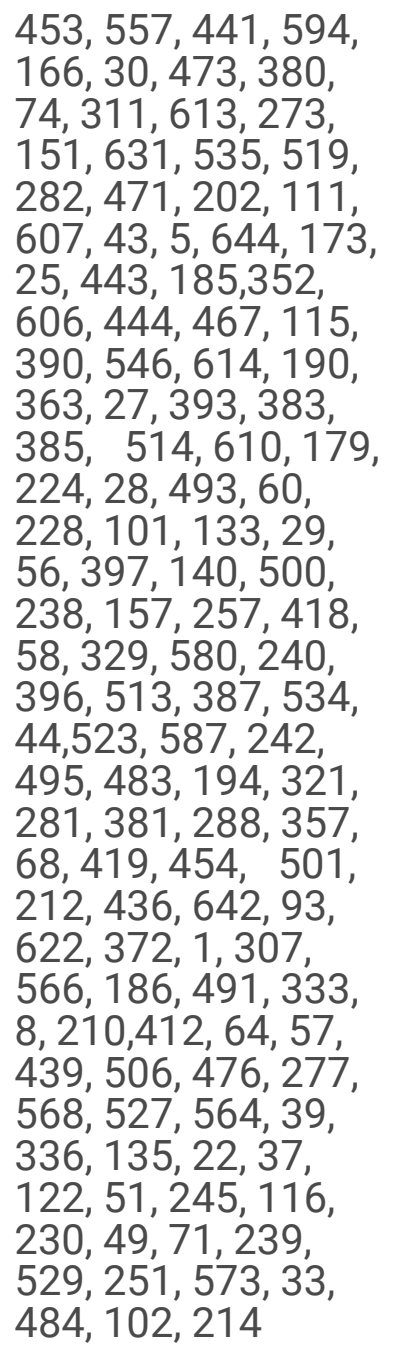 & $\begin{array}{l}(9.303717 \\
\mathrm{N}, \\
41.792390 \\
\mathrm{E}) / 200.29 \\
\mathrm{~km}\end{array}$ & 1110 & 955 & 4.02 & 946.56 & $\begin{array}{l}< \\
0.001\end{array}$ \\
\hline Secondary & $\begin{array}{l}372,93,412,333 \\
476,506,453,491, \\
441,557,594,30 \\
25,166,\end{array}$ & $\begin{array}{l}(8.949349 \\
\mathrm{N}, \\
41.312400 \\
\mathrm{E}) / 91.51 \\
\mathrm{~km}\end{array}$ & 496 & 453 & 3.73 & 480.60 & $\begin{array}{l}< \\
0.001\end{array}$ \\
\hline
\end{tabular}

\section{Spatial interpolation:}

For the prediction of khat chewing prevalence for unsampled areas we used ordinary Kriging geostatistical interpolation. Based on geostatistical Kriging analysis, in 2016 EDHS exclusively Dira Dawa, Harari, some part of Oromia, Somai and Some part of SNNPR had a prevalence of less $39.14 \%$ to 100\%(Figure 7) 


\section{Factors affecting chewing Khat among adult male in Ethiopia}

In the bivariate analysis, age group, sex, marital status, residence, religion, Educational status, region, wealth index, media exposure, working status, and alcohol drinking were associated factors with khat chewing at a p-value of less than or equal to 0.2 . Consequently, these variables were subjected to multivariable analysis, and it was noted that age group, marital status, religion, region, media exposure, working status, and alcohol drinking were statistically significant variables associated with khat chewing at a p-value of 0.05

The odds of chewing khat among Ethiopian adults age group 30-44 and $45-59$ increase by $44 \%$ and $25 \%$ as compared to age group 15-29 years ( $\mathrm{AOR}=1.44,95 \% \mathrm{Cl}$ : 1.27, 1.62), (AOR=1.25, 95\% Cl: 1.08, 1.46) respectively. Being single increases the odds of chewing Khat by $86 \%$ as compared to married adults $(\mathrm{AOR}=1.86,95 \% \mathrm{Cl}: 1.64,2.12)$. The odds of chewing Khat among Muslim religion followers were 4.91 times higher as compared to Orthodox religion followers ( $A O R=4.91,95 \% \mathrm{Cl}: 3.69,8.19)$. The odds of chewing chat decrease by $33 \%$ among media exposed adults as compared to non exposed (AOR=0.77, $95 \% \mathrm{Cl}: 0.68,0.86)$. The likelihood of chewing chat among alcohol; drinkers were 2.91 times higher as compared to nondrinkers ( $\mathrm{AOR}=2.91,95 \% \mathrm{Cl}$ : 2.49, 3.39). The odds of khat chewing varies from region to region (Table 2).

\section{Discussion}

The prevalence of ever khat chewing among male adults age 15-59 in this study was $3418(27.14 \%)$ with $95 \% \mathrm{Cl} 26.37-27.92 \%$. This finding is lower than the study done in Jimma town (37.8\%)(15), Butajira (55.7\%)(17) and in In Nekemte town (43.5\%)(16). The discrepancy might be due to more khat is available in Jimma, Butajira, and Nekemt when compared with national distribution. However, this finding is higher than the study done in 2011 EDHS survey in Ethiopia was (15.3\%)(13), 2015 National Non-Communicable Disease STEPS the lifetime prevalence of khat chewing was (19\%)(14) and in Dera woreda ever khat chewing was (19.9\%) (18). In the former, the prevalence was the last 30 days duration of khat chewing whereas the current finding was a lifetime. For the second and the third studies, the difference might be nowadays the cultivation of khat is higher when compared within the previous time and in the current study only men were included but in the previous studies, both men and women were included.

The current finding was lower than the study finding of Somalis living in London the prevalence in the last one-week was 67\% (11), in Saudi Arabia and Yemen, the prevalence of khat chewing was 36\%(12) and $72 \%$ (9) respectively. In Yemeni men, the prevalence of khat chew was 90\%(10). The discrepancy might be due to khat chewing is a deeply entrenched religious and socio-cultural tradition(6).

In this finding, different factors of khat chewing were assessed by the logistic regression model. Individuals whose residency of Afar, Amhara, Oromia, Somali, Benishangul, SNNPR, Gambela, Harari, Addis Ababa, and Dire Dawa had higher odds of khat use when compared with Tigray. This study is in 
line with EDHS 2011 Ethiopia (13) the reason might be due to the fact that nowadays khat is cultivated throughout Ethiopia due to both socioeconomic and agroecological have contributed to khat farming expansions. The powerful force has perhaps been increased market prospects and prices of khat(26).

The odds of chewing khat among Ethiopian adults age group 30 to 44 and $45-59$ increase by $44 \%$ and $25 \%$ respectively as compared to the age group 15-29 years. As the age increases, khat chewing behavior is increase which is supported by the 2011 EDHS data(13).

The odds of chewing khat among single individuals were about two times as compared to married. This might be due to individuals who are single are high risk for substance use and unmarried individuals are positively associated with khat chewing(16). The odds of chewing Khat among Muslim religion followers were about five times higher as compared to Orthodox religion followers which are supported by the research done in EDHS, 2011 (13), Chiro town(19), Dera woreda(18) and Butajira (17). This could be due to the fact that khat use was acceptable in the socio-cultural and functional purposes with a restriction of the frequency, amount, and type of khat(27). Another reason might be to get maximum concentration level during praying, increase socialization, confirming norms and for stabilizing emotions(17)

The odds of chewing khat decrease by $33 \%$ among media exposed adults as compared to their counterparts. This could be due to the fact that individuals who read magazines. newspapers, listen to the radio and watching television had the awareness of the bad consequence of khat use like; depression, anxiety, sleep disorder, conflict in the family, reduced appetite, neurological, and dental problems less likely to chew khat(21-24).

The odds of khat chewing is increased by $91 \%$ among alcohol drinkers when compared with a nondrinker. This is consistent with another finding; harmful drinking is common among khat users that account for $53.9 \%$ (28). The possible reason might be alcohol drinking is used to break the stimulating effect of khat therefore alcohol is helpful for sleep and used as self-treatment from khat induced distress (25).

The odds of khat chewing was decreased by $55 \%$ among individuals who have work when compared with counterparts. Perhaps, the jobless individuals spent their time with khat chewing.

This study has strengths of nationally representative data and advanced statistical models were used to account correlations within clusters. However, this study has limitations of the cross-sectional nature of the study may not indicate true causality. In addition, the effects of the health system and health worker factors were not assessed.

\section{Conclusions}

The prevalence of chewing khat in Ethiopia was higher when compared with other similar studies. Men in older age groups, single, alcohol drinkers, Muslim religion follower, and work status should be given spatial attention in reducing the prevalence of chewing khat. Therefore, it is good to teach the health impact of khat chewing through media. 


\section{Declaration}

\section{Ethics approval and consent to participate}

Since the data is secondary and we receieved permission letter from measure DHS at www.measuredhs.com. According to the EDHS 2016 report written informed consent from study participants age less than 16 was obtained from the guardian. The detailed of the report can be access at (3) .

\section{Availability of data and materials}

The datasets used during the current study are available from the corresponding author

\section{Funding}

We didn't receive external funds for this research.

\section{Acknowledgment}

We would like to thank the Ethiopian Central Statistics Agency for providing us with all the relevant secondary data used in this study. Finally, we would like to thank all who directly or indirectly supported us.

\section{Consent for publication}

Not applicable.

\section{Competing interests}

The authors declared that they have no competing interests.

\section{Authors' contributions}

ZTT and TAZ conceived the study, involved in the study design, data analysis, drafted the manuscript and critically reviewed the manuscript. Both authors read and approved the final manuscript.

\section{Abbreviations}


AOR

Adjusted Odds Ratrio; Cl:Confidence Interval;COR:Crude Odds Ratio; LLR:Likelihood Ratio; RR:Relative Risk SNNPR:South Nation Nationalies of People Regions

\section{References}

1. Kennedy JG, Teague J, Rokaw W, Cooney E. A medical evaluation of the use of qat in North Yemen. Social Science \& Medicine. 1983;17(12):783-93.

2. Cox G, Rampes H. Adverse effects of khat: a review. Advances in psychiatric treatment. 2003;9(6):456-63.

3. Krizevski R, Dudai N, Bar E, Lewinsohn E. Developmental patterns of phenylpropylamino alkaloids accumulation in khat (Catha edulis, Forsk.). Journal of ethnopharmacology. 2007;114(3):432-8.

4. Nyongesa AW, Onyango DW. Khat: A Boon or bane to humanity. 2010.

5. Elmi AS. The chewing of khat in Somalia. Journal of ethnopharmacology. 1983;8(2):163-76.

6. Thomas S, Williams T. Khat (Catha edulis): A systematic review of evidence and literature pertaining to its harms to UK users and society. Drug Science, Policy and Law. 2013;1:2050324513498332.

7. Dhaifalah I, Santavy J. Khat habit and its health effect. A natural amphetamine. Biomed Pap Med Fac Univ Palacky Olomouc Czech Repub. 2004;148(1):11-5.

8. Stefan J, Mathew B. Khat chewing: an emerging drug concern in Australia? Australian and New Zealand Journal of Psychiatry. 2005.

9. CRIME UNOODA. World DDrug Report. United Nations New York: 2012.

10. Ward C, Gatter P. Qat in Yemen-towards a policy and action plan. World Bank, Sana'a, Yemen. 2000.

11. Griffiths P, Gossop M, Wickenden S, Dunworth J, Harris K, Lloyd C. A transcultural pattern of drug use: qat (khat) in the UK. The British Journal of Psychiatry. 1997;170(3):281-4.

12. Mahfouz MS, Rahim B-eE, Solan YM, Makeen AM, Alsanosy RM. Khat chewing habits in the population of the Jazan region, Saudi Arabia: prevalence and associated factors. PloS one. 2015;10(8):e0134545.

13. Haile D, Lakew Y. Khat chewing practice and associated factors among adults in Ethiopia: further analysis using the 2011 demographic and health survey. PloS one. 2015;10(6):e0130460.

14. Teklie H, Gonfa G, Getachew T, Defar A, Bekele A, Bekele A, et al. Prevalence of Khat chewing and associated factors in Ethiopia: Findings from the 2015 national Non-communicable diseases STEPS survey. Ethiopian Journal of Health Development. 2017;31(1):320-30.

15. Damena T, Mossie A, Tesfaye M. Khat chewing and mental distress: a community based study, in jimma city, southwestern ethiopia. Ethiopian journal of health sciences. 2011;21(1):37-46.

16. Wondemagegn AT, Cheme MC, Kibret KT. Perceived psychological, economic, and social impact of khat chewing among adolescents and adults in Nekemte Town, East Welega Zone, West Ethiopia. BioMed research international. 2017;2017. 
17. Alem A, Kebede D, Kullgren G. The prevalence and socio-demographic correlates of khat chewing in Butajira, Ethiopia. Acta Psychiatrica Scandinavica. 1999;100:84-91.

18. Zeleke A, Awoke W, Gebeyehu E, Ambaw F. Khat chewing practice and its perceived health effects among communities of Dera Woreda, Amhara region, Ethiopia. Open Journal of Epidemiology. 2013;3(04):160.

19. Dagnew GG. KHAT CHEWING PRACTICE ITS PERCEIVED HEALTH EFFECT AND ASSOCIATED PROBLEMS WITH KHAT CHEWING AMONG COMMUNITIES OF CHIRO TOWN. . Int J Adv Res. 2018;6(10).

20. Yahya A, Rajeshwar Y, Eticha T, Kahsay G, Ali D, Gebretsadik H, et al. Socio-Economic and Health Effects of Khat Chewing in Mekelle, Tigray Region, Ethiopia Human Journal. 2016;8(1).

21. Etana MB. Economic and Social Impacts of Khat (Catha edulis Forsk) Chewing Among Youth in Sebeta Town, Oromia Ethiopia. Biomedical Statistics and Informatics. 2018;3(2):29.

22. Elhadrani AM, AlHoot MA. An association between khat and diabetes. Egypt Journal of Surgery. 2000;19:16-9.

23. Ageely HM. Health and socio-economic hazards associated with khat consumption. Journal of family \& community medicine. 2008;15(1):3.

24. Legesse TG, Takle ZJ, Best MGs. Effect of Khat and Associated Factors on Nutritional Status among Khat Chewers at Gulelle Sub-city, Addis Ababa, Ethiopia 201;7(1).

25. Mihretu A, Teferra S, Fekadu A. Problematic khat use as a possible risk factor for harmful use of other psychoactive substances: a mixed method study in Ethiopia. Substance abuse treatment, prevention, and policy. 2017;12(1):47.

26. Hailu Feyisa T, Aune J. Khat expansion in the Ethiopia highlands: effects on the farming system in Habro distrit. MOUNTAIN RESEARCH AND DEVELOPMENT. 2003;23(2):185-9.

27. Mihretu A, Teferra S, Fekadu A. What constitutes problematic khat use? An exploratory mixed methods study in Ethiopia. Substance abuse treatment, prevention, and policy. 2017;12(1):17.

28. Tsegay G. Psychoactive substances use (khat, alcohol and tobacco) and associated factors among Debre Markos University Students, North-West Ethiopia, 2013. 2014.

\section{Figures}


$\AA^{N}$

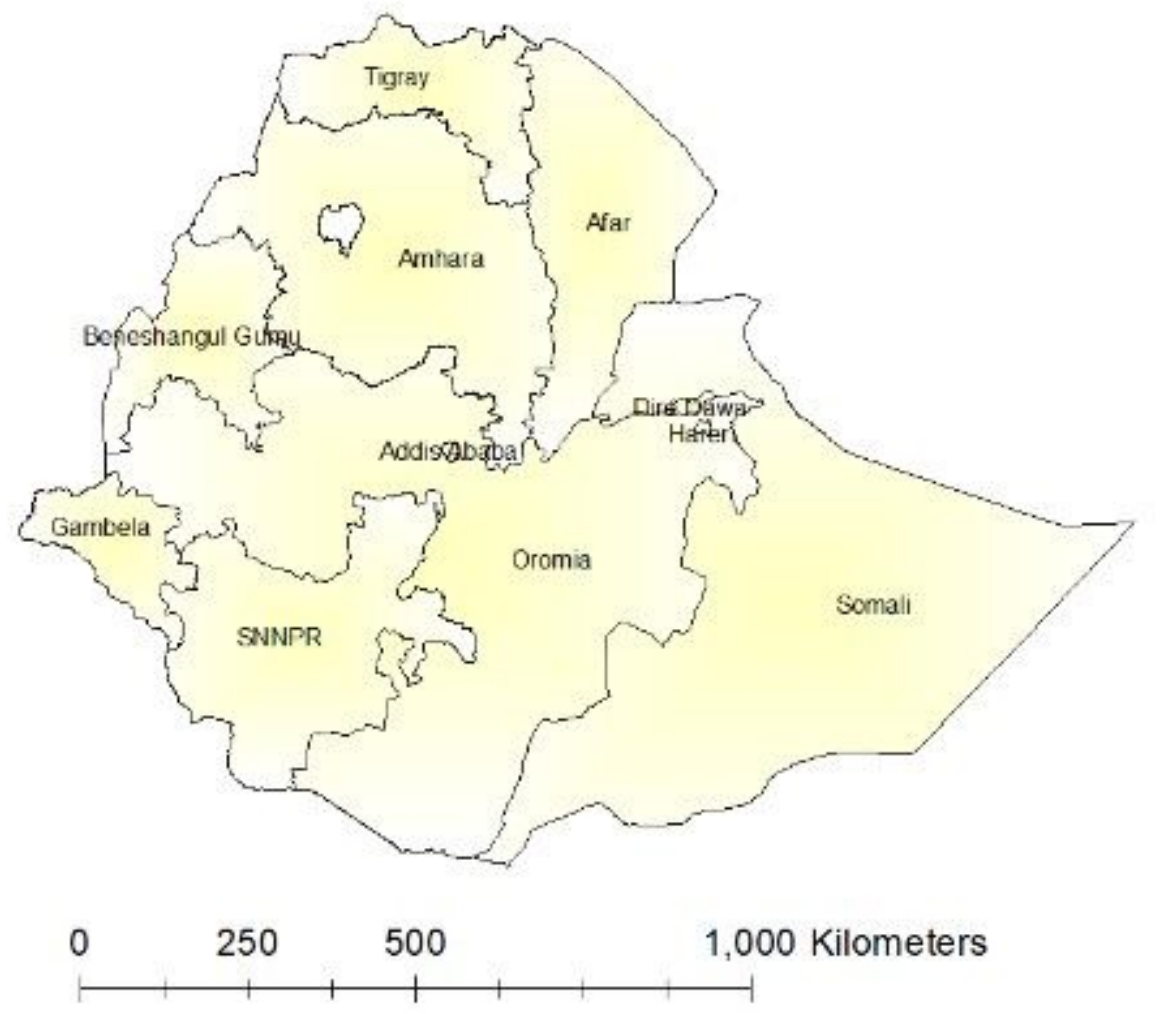

\section{Figure 2}

Study areas of nine regions and two city admirations in Ethiopia, EDHS 2016 


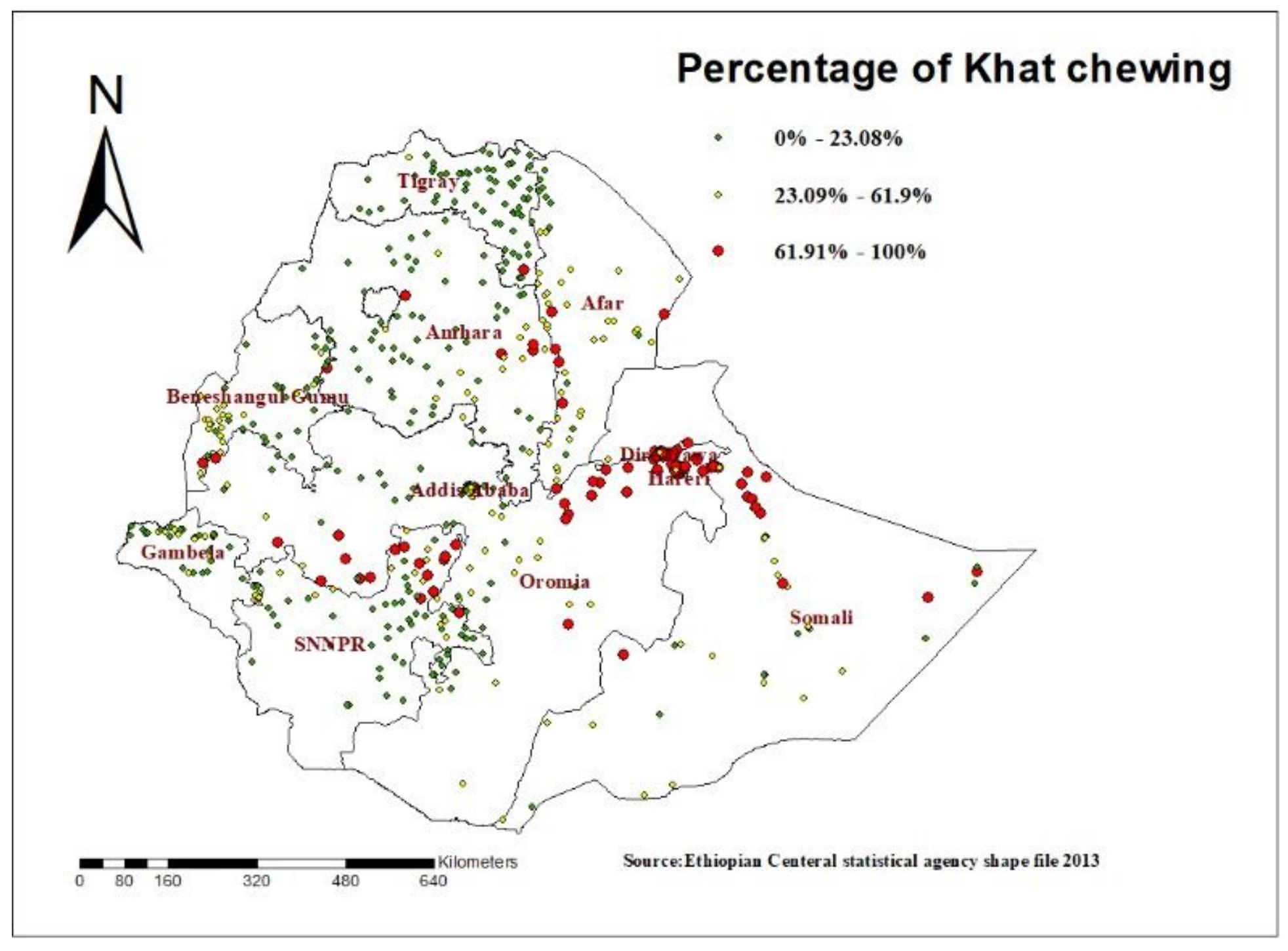

Figure 4

Spatial Distribution of Khat chewing among adults age 15-59 across regions of the country, EDHS 2016 


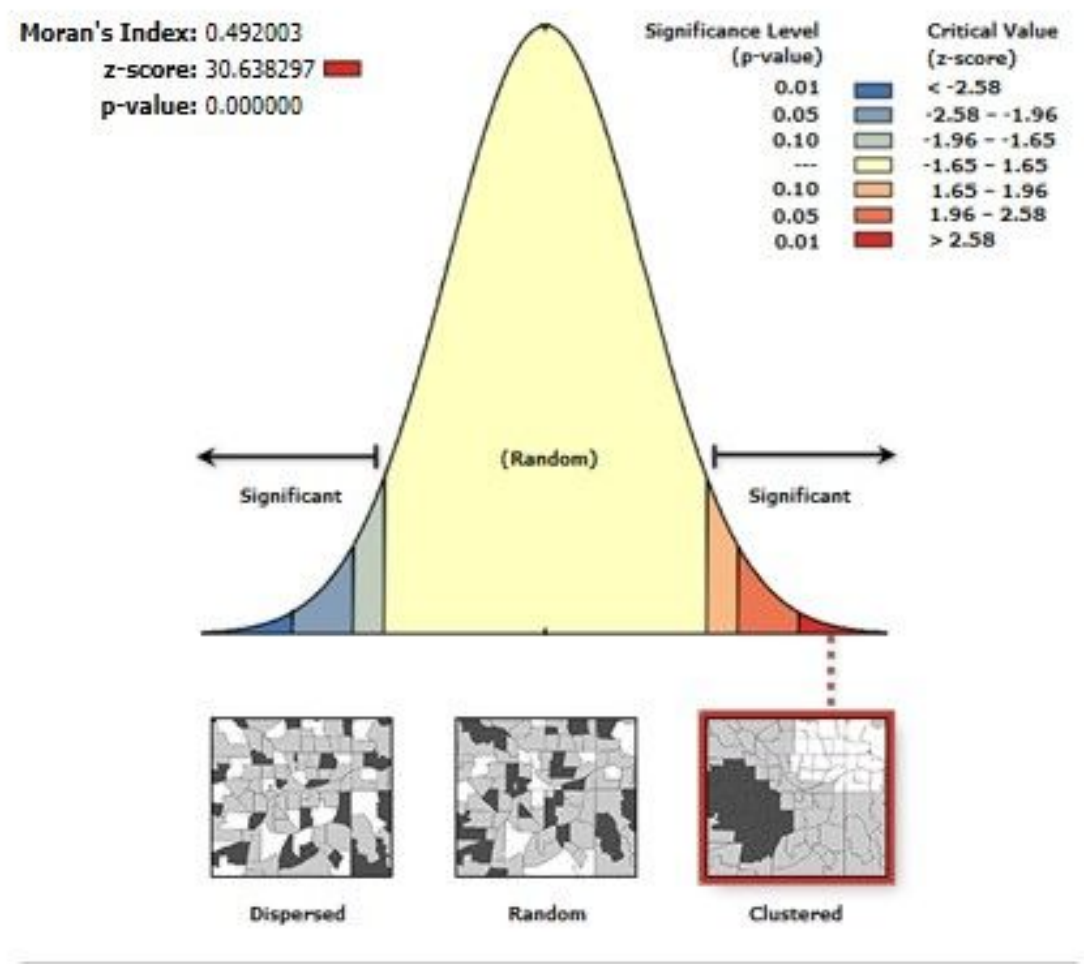

Given the $z$-score of 30.6382974838 , there is a less than $1 \%$ likelihood that this clustered pattern could be the result of random chance.

\section{Figure 6}

Spatial autocorrelation of Khat chewing among adults age 15-59 across regions of the country, EDHS 2016 
Spatial Autocorrelation by Distance

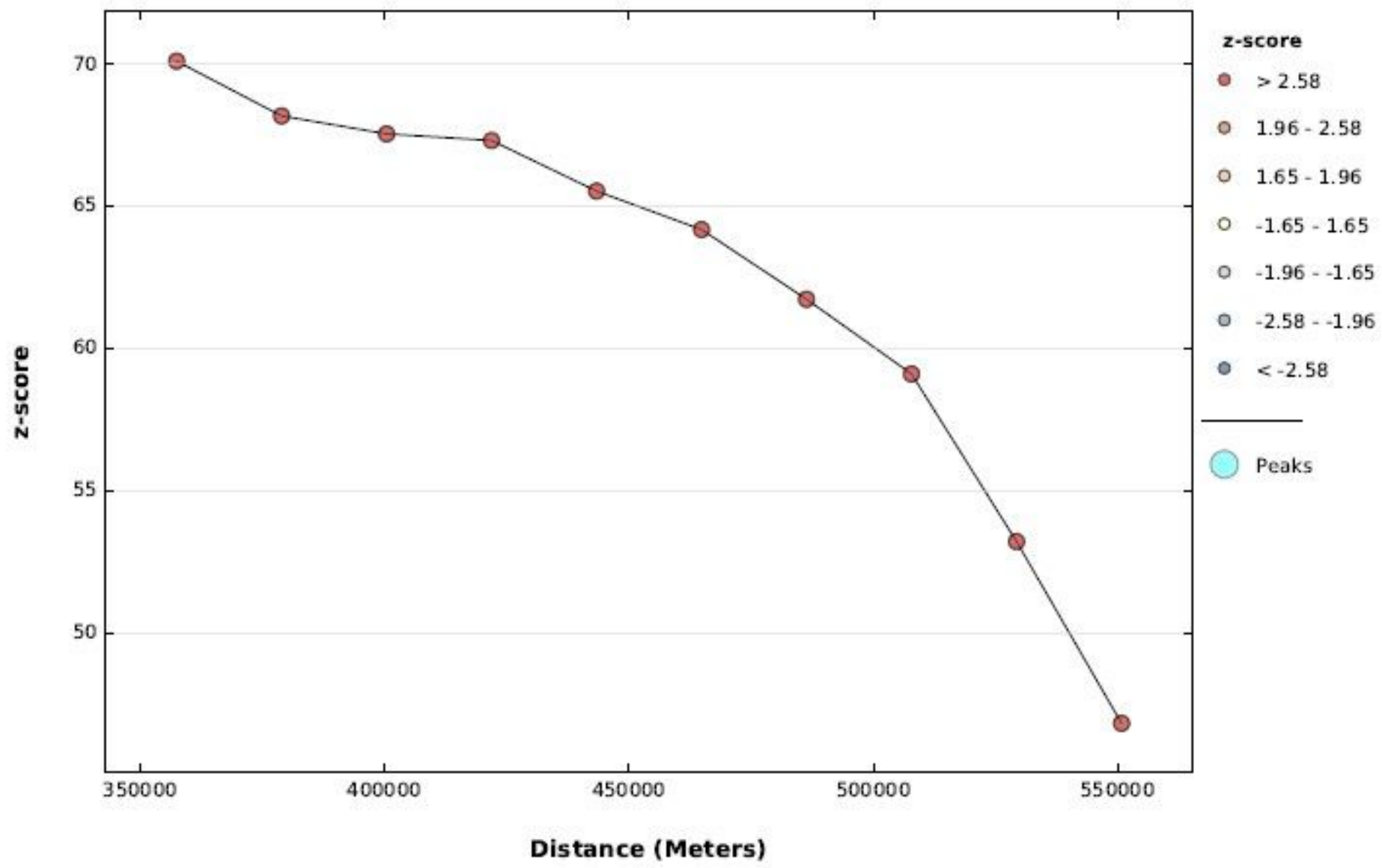

Figure 7

Spatial incremental autocorrelation of chewing khat in Ethiopia EDHS 2016 

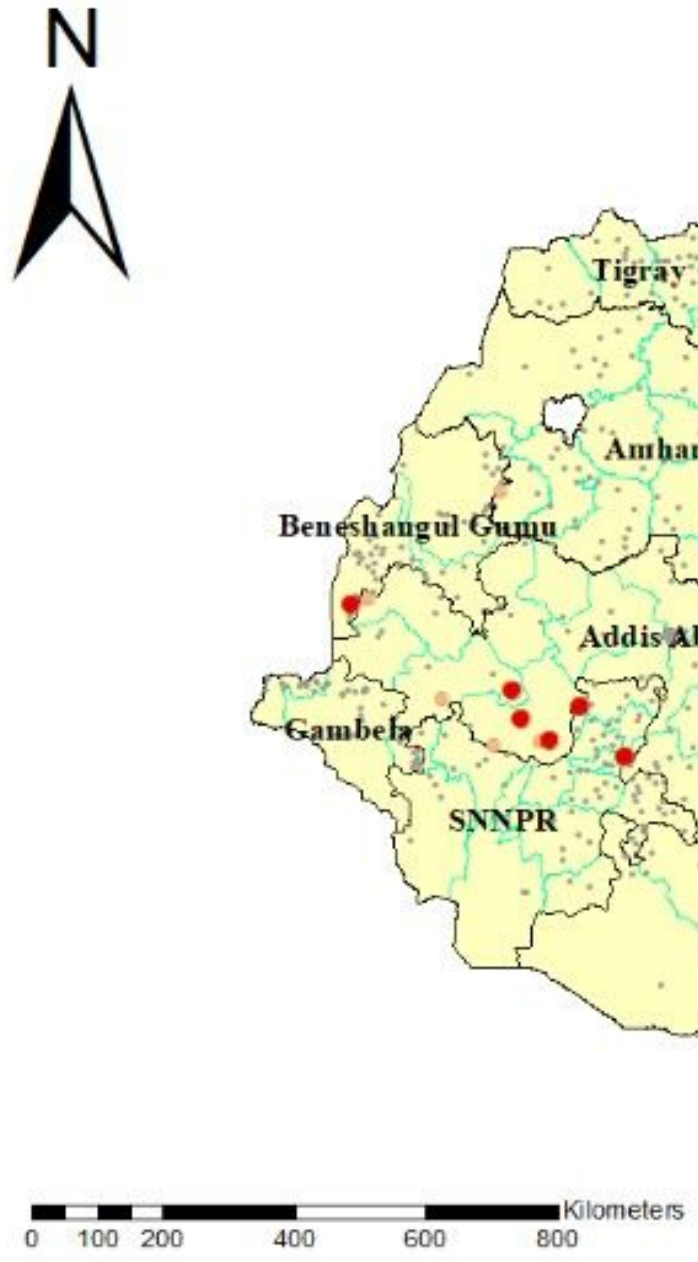

\section{Hot Spot Analysis}

- Cold Spot-99\% Confidence

- Cold Spot - 95\% Confidence

- Cold Spot - 90\% Confidence Not Signific cant

- Hot Spot - $\mathbf{9 0 \%}$ Confidence

- Hot Spot - 95\% Confidence

- Hot Spot - 99\% Confidence

\section{Figure 9}

Hot Spot Analysis of khat chewing in Ethiopia EDHS 2016 

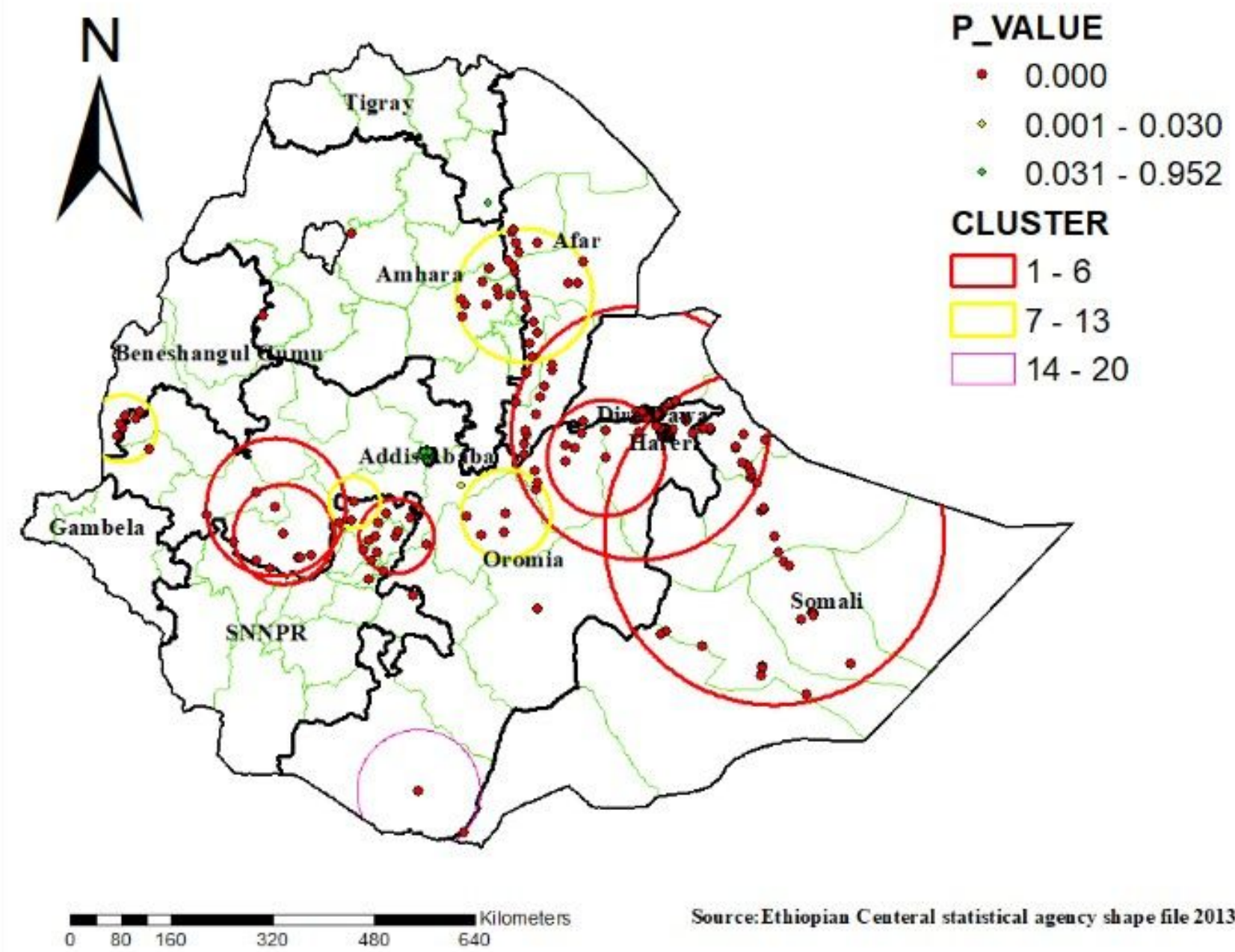

Source:Ethiopian Centeral statistical agency shape file 2013

Figure 12

Spatial Scan statistics of khat chewing in Ethiopia EDHS 2016 

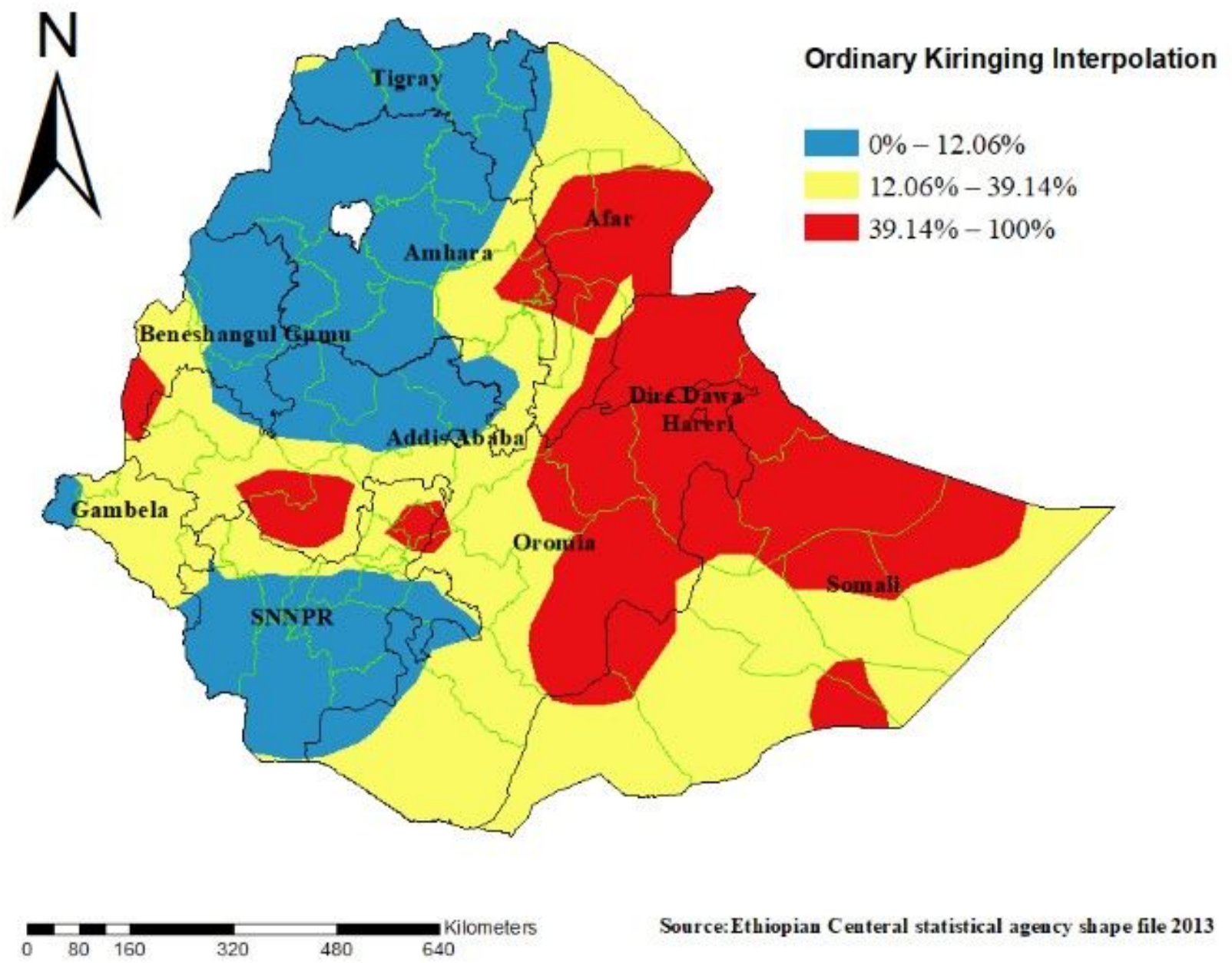

Source: Ethiopian Centeral statistical agency shape file 2013

Figure 14

Spatial interpolation of khat chewing among males in Ethiopia,EDHS 2016 